\title{
Barbon Versus Locke Sobre o Valor da Moeda
}

\author{
Mauricio C. Coutinho
}

Submetido: 22 de setembro de 2010; aceito para publicação: 31 de agosto de 2011

Resumo: $\mathrm{O}$ artigo discute as posições contrastantes de Nicholas Barbon e John Locke no debate monetário inglês sobre a "valorização do dinheiro" dos anos 1690. Embora referidos às condições do sistema monetário inglês da época, os temas e argumentos do debate foram fundamentais na formação da teoria monetária e da teoria econômica, entre o final do século XVII e o século XVIII. O artigo acompanha a crítica de Barbon a Locke, e procura efetuar um sumário da teoria monetária de Locke, cuja importância no debate econômico se estendeu por 150 anos.

Palavras-Chave: Barbon, Locke, valorização do dinheiro, preços, teoria quantitativa da moeda

\begin{abstract}
The paper contrasts Nicholas Barbon's and John Locke's positions, in the 1690's English monetary debates about raising the money. Although Barbon's and Locke's arguments were referred to the English monetary setting of the 1690's, it can be argued that the issues pointed at and the theoretical achievements of the debates were instrumental to the constitution of monetary economics and of economic theory itself, a process unfolded in the late seventeenth century and eighteenth century. Locke's theory, in special, stood as a benchmark to monetary theory for a 150 years long period. The text follows Barbon's review of Locke's position on monetary issues, and tries to make an assessment of both authors contributions to monetary economics.
\end{abstract}

Trabalho desenvolvido em pesquisa apoiada pela FAPESP. A presente versão do artigo foi beneficiada pelos comentários do referee anônimo da Revista.

Mauricio C. Coutinho

Professor Titular da Universidade de Campinas - UNICAMP - Endereço para contato: Instituto de Economia UNICAMP - Rua Pitágoras 353 - Cidade Universitária Zeferino Vaz - CEP:13083857- Campinas - SP - Email: mcout@eco.unicamp.br 
Keywords: Barbon, Locke, raising the money, prices, quantity theory of money

JEL Classification: B10

\section{Introdução}

Um dos fenômenos mais marcantes da história da teoria monetária é a prolongada influência dos ensaios monetários de John Locke (1632-1704). Escritos nos anos 1690, em resposta à prolongada crise econômica inglesa resultante da Guerra dos Nove Anos (1688-1697), os principais ensaios monetários de Locke - Some Considerations of the Consequence of the Lowering of Interest, and Raising the Value of Money (Locke, 1691) e Further Considerations concerning Raising the Value of Money (Locke, 1696) - representam um desenvolvimento de ideias antecipadas em estudos anteriores e menos substanciais do próprio autor. ${ }^{1}$ Constituem, claramente, uma resposta de momento a dois temas que por algumas décadas agitaram o debate monetário inglês: a tentativa de redução por lei da taxa de juros e a "valorização da moeda", ou seja, o estabelecimento do novo conteúdo metálico da moeda por meio de uma recoinage, tornada necessária pela elevada degradação do meio circulante inglês no final do século XVII.

Apesar de voltada a questões de circunstância, a contribuição de Locke tornou-se referência obrigatória nos debates sobre moeda, circulação e juros por mais de 150 anos. A lista de teóricos que mencionam Locke e criticam-no ou apoiam-se em seu nome para formular contribuições próprias, é significativa: Cantillon, Galeani, Steuart, Turgot, Adam Smith, Thornton, Say, Marx... Os pontos em questão são tanto aqueles em relação aos quais sua contribuição é considerada emblemática e precursora, como a teoria quantitativa da moeda e o mecanismo de ajustamento automático do balanço de pagamentos (specie-flow mechanism), quanto a controversa e geralmente objetada concepção de "valor intrínseco" do dinheiro de prata, estabelecido "por consentimento". A determinação do valor da moeda "pelo con-

\footnotetext{
${ }^{1}$ Estes estudos sobre taxa de juros, escritos entre 1668 e 1674 para o patrono de Locke, Shaftesbury, criticavam o influente livro de Josiah Child, Brief Observations concerning Trade, and Interest of Money, publicado em 1668 e republicado em 1690. Ver a respeito Eltis (1995) e Letwin (1963).
} 
sentimento" foi uma ideia criticada por contemporâneos de Locke, como Barbon, assim como por uma ilustre linhagem de grandes economistas monetários do século XVIII - Law, Cantillon, Galeani, Turgot -, os quais se recusaram a admitir a existência de um valor especial na moeda, entendendo que também neste caso valiam os princípios gerais do valor, aplicáveis a qualquer mercadoria.

Na longa listagem dos críticos monetários de Locke, Nicholas Barbon (1637/1640-c.1698) ocupa um lugar especial. Contemporâneo de Locke, envolvido nos debates sobre taxa de juros e "valorização da moeda" travados em panfletos e no Parlamento, ${ }^{2}$ Barbon, diferentemente dos críticos de Locke do século XVIII, não adotou a concepção de que a moeda tem seu valor determinado como o de qualquer outra mercadoria. Neste aspecto, distinguiu-se da linha dominante em economia monetária, a qual, do final do século XVII até o início do XIX relacionava o valor da moeda a sua natureza mercantil.

Os principais textos econômicos de Barbon - A Discourse of Trade (Barbon, 1690) e $A$ Discourse Concerning Coining the New Money Lighter (Barbon, 1696) - também merecem atenção por suas contribuições originais à economia e pelo pioneirismo na negação de princípios mercantilistas. ${ }^{3}$ Considere-se ainda que $A$ Discourse Concerning Coining the New Money Lighter apresenta o mérito adicional de constituir uma espécie de guia às ideias de Locke, já que contém um sumário muito bem elaborado da teoria monetária deste autor. Se levarmos em conta que os textos monetários de Locke não primam pela clareza e objetividade, pode-se dizer que a sistematização efetuada por Barbon representa em si uma contribuição. Pela concisão e clareza, a sistematização de Barbon contribui para o esclarecimento das ideias de ambos os autores, bem como do debate monetário do final do século XVII.

O objetivo do presente artigo é exatamente o seguinte: por meio de uma revisão dos escritos econômicos de Locke e Barbon dos anos 1690, contribuir para o entendimento de temas e autores fundamentais à formação do pensamento monetário. $\mathrm{O}$ artigo toma como fio condutor os argumentos de Barbon, desdobrando-se em quatro seções, afora a presente Introdução. A segunda seção trata das cir-

\footnotetext{
${ }^{2}$ Barbon foi mesmo membro do Parlamento entre 1690 e 1695. Para um pequeno esboço biográfico, ver o verbete do New Palgrave (Vickers, 2008) e também Letwin (1963).

${ }^{3}$ Schumpeter (1954) destaca o caráter pioneiro de Barbon e o credencia como um dos grandes economistas ingleses do século XVII. Hutchison (1988) também destaca o pioneirismo de Barbon.
} 
cunstâncias históricas, ou seja, procura recompor de modo muito esquemático os principais elementos do debate monetário inglês dos anos 1690. A terceira apresenta o pensamento monetário de Barbon suas próprias ideias e os pontos de objeção a Locke. A quarta destaca os pontos fortes da argumentação de Locke, ou os pontos fracos da argumentação de Barbon, particularmente no que se refere ao valor da moeda, taxa de câmbio e par of money (relação de troca entre duas peças de moeda). A título de conclusão, a seção final recompõe alguns dos elementos centrais da teoria monetária de Locke.

\section{O Debate Monetário Inglês no Final do Século XVII ${ }^{4}$}

Antes de entrarmos no debate monetário inglês do final do século XVII, convém destacar certas características dos sistemas monetários metálicos que são essenciais ao entendimento do debate sobre o valor da moeda. Os sistemas monetários metálicos caracterizam-se pela presença de moedas formadas por ligas metálicas de ouro, prata ou cobre, cunhadas por uma autoridade monetária nacional. $\mathrm{O}$ valor de face da moeda deve guardar relação com o valor de mercado do metal, exceto no caso das peças de cobre, destinadas às pequenas transações, para as quais se aceitava uma relação apenas remota entre o valor do cobre contido na moeda e o valor indicado pelo selo da casa da moeda.

Sistemas nacionais que cunhavam e admitiam a circulação de moedas baseadas em dois metais - ouro e prata - tinham de conviver com um problema especial, a flutuação do valor relativo dos dois metais e a dificuldade de fixar uma relação de troca entre ambos. Além disso, e de modo geral, os sistemas monetários preservavam, a par das moedas efetivamente cunhadas e em circulação com suas diversas subdivisões, uma moeda "ideal" ou um padrão monetário que não constituía meio circulante; por exemplo, a sterling pound inglesa e a livre tournois francesa. O "preço" das peças em circulação era então estabelecido pela relação de troca entre elas e o padrão monetário, havendo na fixação deste preço certo espaço para arbítrio; vale dizer, a autoridade monetária poderia tentar estipular, dentro de certos limites, uma relação de troca entre as peças em circulação e o padrão

\footnotetext{
${ }^{4}$ A reconstituição baseia-se em Kelly (1991), Eltis (1995), Kindleberger (1993). Um bom esclarecimento das características dos sistemas monetários metálicos e dos métodos e significados dos movimentos de "valorização do dinheiro" encontra-se no clássico Da Moeda, Galeani (1751).
} 
monetário que não atendesse ao efetivo preço de mercado do metal. ${ }^{5}$ Desse modo, a par dos ajustamentos "naturais" na relação de troca entre o padrão monetário e as peças metálicas correntes, provocados pelas variações do valor de mercado de ouro e prata, a autoridade monetária poderia alterar esta relação de três modos: em primeiro lugar, modificando a liga metálica ou o teor de ouro ou prata da moeda; em segundo lugar, alterando o peso das peças monetárias em circulação. Para que não houvesse duplicidades no sistema monetário (duas moedas com mesma denominação e conteúdo distinto de metal precioso), esses dois procedimentos deveriam levar em certo momento a uma "recunhagem" (recoinage), ou seja, ao recolhimento do meio circulante para fusão e adaptação aos novos padrões; em terceiro lugar, o valor da moeda poderia ser modificado sem recunhagem, simplesmente alterando-se a relação de troca oficial entre o padrão monetário e as peças em circulação. ${ }^{6}$

Estes métodos de "valorização do dinheiro" - na linguagem da época, raising the money, enhancement, debasement, ou ainda raising the money in denomination, quando adotado o terceiro método - foram utilizados por soberanos desejosos de melhorar a situação das finanças públicas, seja por provocarem a desvalorização da dívida pública medida em metais preciosos, seja por existir certa letargia no ajustamento dos preços dos serviços e pessoal pagos pelo governo. O soberano conseguiria então trocar mais metal precioso por menos, ao saldar dívidas contratadas em moeda antiga na nova moeda e ao pagar a preços da moeda antiga serviços executados em tempos de moeda nova. Na Inglaterra, as "valorizações do dinheiro" efetuadas por Henrique VIII ficaram célebres como um método de recomposição das finanças públicas quase tão eficaz quanto a desapropriação das terras da igreja.

A recunhagem é um empreendimento complexo que deve ser acompanhado por diversas decisões e providências acessórias, mas não menos decisivas. As autoridades monetárias têm de estabelecer os prazos nos quais a moeda antiga deixará de circular (perda de poder liberatório), o ônus do custeio da recunhagem - a ser arcado pela

\footnotetext{
${ }^{5}$ A propósito da relação entre padrão monetário e meio circulante, Boyer (2007).

${ }^{6}$ Mais propriamente, alterando a "Mint rate", que representa duas coisas: o valor a que a peça seria considerada corrente no país, e o preço de fato pago pela Casa da Moeda pelo ouro e prata. A respeito, ver Kelly (1991). A relação entre o "Mint rate" e o valor do metal em barra no mercado orientava a conversão de bullion em moeda, e vice-versa; ou seja, a suficiência ou escassez de meio circulante.
} 
Casa da Moeda, pelo detentor da moeda antiga, lançado sobre um tributo geral? - e, particularmente, a relação entre os preços das peças metálicas retiradas de circulação e as que são entregues de volta ao público. Enfim, quem arcaria com o custo total da "valorização do dinheiro".

É preciso considerar ainda que as peças metálicas em circulação perdiam peso em virtude de desgaste natural ou por atos fraudulentos de raspagem (clipping). Na medida em que moedas com mesmo valor de face e conteúdos diversos de metal fossem aceitas nas transações, não sobreviriam problemas de circulação no território nacional. No entanto, a deterioração expressiva do meio circulante, em geral provocada por fraudes, poderia levar à rejeição das moedas de pior qualidade e, naturalmente, à retirada de circulação daquelas de maior teor de metal precioso para entesouramento ou realização de operações de arbitragem no mercado internacional.

Estes movimentos traduzem-se em escassez de moeda metálica no território nacional, o que motivava acesos debates sobre escassez de moeda, impactos nos preços, na taxa de câmbio, nos juros, utilização de meio circulante de outras nações nas transações internas - debates que em muito contribuíram para a formação do pensamento econômico. De todo modo, deterioração do meio circulante, escassez de meio circulante (com desaparecimento das peças de prata) e a imposição de uma recunhagem foi o caso expresso da Inglaterra na década final do século XVII e no início do XVIII.

$\mathrm{Na}$ realidade, o quadro inglês era mais complexo. As moedas de prata, que compunham o grosso do meio circulante, haviam sofrido perda de valor por raspagem. A Casa da Moeda passou em 1663 a emitir, com o auxílio de uma nova prensa mecânica, moedas de valor integral e com bordas marcadas, menos suscetíveis à falsificação. Criou-se um padrão monetário duplo - moedas antigas e novas -, o qual estimulou o desaparecimento das moedas novas e de valor pleno. Em decorrência, surgem propostas de alteração do valor legal das moedas novas, ou de redução de seu conteúdo de metal precioso. Como veremos, Locke opôs-se às duas alternativas sob o argumento de que seriam inflacionárias e/ou fraudadoras de contratos estabelecidos em moeda antiga. Estes argumentos, desenvolvidos no ano de 1690 e publicados em Some Considerations... (Locke, 1691), viram-se reforçados pela edição pelo Parlamento de uma nova lei para cortar a 
taxa de juros de 6 para 5\%, em 1692, e pela progressiva deterioração do meio circulante e das finanças públicas inglesas. A guerra contra a França, iniciada em 1689, levou à eclosão de uma crise aberta em 1695, caracterizada por deterioração do balanço de pagamentos (agravada pela perda de canais tradicionais de comércio exterior), queda do nível de atividades e drenagem de prata para o exterior para compensar as letras de câmbio a descoberto. Cabe lembrar que os sistemas monetários metálicos tinham o déficit ou superávit do balanço de pagamentos como o principal meio de redução/elevação do meio circulante. E cabe assinalar ainda que o sistema monetário inglês atravessara quase todo o século XVII em condições de subfixação da Mint rate da prata, o que já provocara uma evasão a longo prazo da prata e a progressiva difusão de moeda de ouro como meio circulante. Por outro lado, a criação do Banco da Inglaterra, em 1694, levaria à progressiva difusão das bank-notes - um fenômeno cuja extensão não foi, à época, devidamente avaliado pelos debatedores monetários, Locke inclusive.

De todo modo, entre 1694 e 1695 a recusa em aceitar as moedas de prata deterioradas chegou a seu auge. A falta de um padrão de valor aceitável afetou seriamente o comércio, e a aquisição de mercadorias baratas no mercado inglês com ouro pelos estrangeiros acabou por acentuar a escassez de mercadorias no mercado interno e a drenagem das moedas de prata para o exterior. A deflação, acompanhada por queda do nível de produção, foi seguida de uma reversão na tendência dos preços, tendo o surgimento de pressões inflacionárias agravado a situação de boa parte da população.

Nesta situação de grave crise do balanço de pagamentos, das finanças públicas, do meio circulante e da produção, William Lowndes, secretário do Tesouro, emitiu um diagnóstico alarmista da situação monetária. Apesar de bastante assemelhado ao de Locke quanto aos efeitos disruptivos de uma moeda imprópria, o diagnóstico de Lowndes concluiu pela proposição de medidas na direção contrária às recomendadas por Locke: elevar o valor das moedas ainda intactas em aproximadamente 20\%; recunhar as moedas danificadas; manter a moeda de conta (o sterling pound) a seu valor histórico, o que representaria uma desvalorização de aproximadamente $20 \%$ em relação à prata - ou seja, menos moedas novas seriam utilizadas no pagamento de dívidas estabelecidas anteriormente à reforma monetária -, com a intenção de manter certa relação entre o valor oficial das novas 
moedas e as moedas raspadas ainda em circulação. Admitia-se que $20 \%$ era a proporção representativa da perda média de conteúdo de prata das moedas antigas. Esperava-se que a desvalorização da moeda viesse a atrair maior quantidade de metal para a Casa da Moeda, permitindo elevar o meio circulante.

A proposta de Lowndes levou Locke a reafirmar seu ponto de vista contrário à depreciação do meio circulante em relação ao padrão anterior (Locke, 1696), e sua posição foi a que efetivamente prevaleceu na ocasião. A recunhagem foi feita sem "valorização do dinheiro".

As efetivas consequências da recunhagem sobre a economia inglesa são controversas, porém, em geral se admite que a situação monetária e o crédito público só vieram a estabilizar em meados del697. ${ }^{7}$ A recunhagem, em si, foi completada apenas ao final de 1698, com a completa retirada de moeda de prata deteriorada de circulação. ${ }^{8}$ O quadro inglês na primeira metade da década de 1690 é que forma o pano de fundo da controvérsia entre Barbon e Locke.

\section{Barbon sobre a Moeda}

A amplitude de temas e o pioneirismo fizeram de $A$ Discourse of Trade, de 1690, uma contribuição muito reconhecida pelos historiadores do pensamento econômico. O texto credenciou Barbon como um dos principais proponentes da tese de que as atividades econômicas dependem de uma adequada disponibilidade de meio circulante ou, na linguagem da época, o dinheiro (money) determina o nível de produção (trade). Aliás, o primeiro capítulo ( $\mathrm{O} f$ Trade And The Stock, or Wares of Trade) inicia com uma clássica e abrangente conceituação de trade. ${ }^{9}$

A Discourse of Trade adota ainda uma concepção mercantil e não metálica de riqueza, colidente com alguns dos pressupostos centrais

\footnotetext{
${ }^{7}$ Kelly (1991) pondera os diversos elementos que contribuíram para agravar ou aliviar a situação da moeda, das finanças públicas e da produção no crítico período 1696-1698.

${ }^{8}$ Mas a recunhagem não conseguiu restabelecer completamente a moeda de prata como o meio circulante dominante na Inglaterra. A cunhagem de moeda de prata continuou em nível reduzido, o que levou a Inglaterra a uma nova crise monetária em 1717 e à subsequente adoção do padrão-ouro.

9 "Trade is the Making, and Selling of one sort of Goods for another; The making is called HandyCraft Trade, and the maker an Artificer; The Selling is called Merchandizing, and the Seller a Merchant." (Barbon, 1690, p. 8).
} 
da abordagem mercantilista então dominante. Por não aderir ao cânone da riqueza em metais, e por manifestar certa descrença em mecanismos protecionistas e nas restrições à exportação de metais preciosos, Barbon pode ser visto como um dos pioneiros na superação do pensamento econômico mercantilista.

No texto, segue-se a uma detalhada descrição da natureza das mercadorias (Capítulo 2, Of the Quantity And Quality Of Wares) a defesa do princípio de que o valor das mercadorias depende do uso, e de que o preço ou valor efetivo (present value) é inteiramente determinado no mercado, pela disponibilidade das mercadorias face à demanda. $\mathrm{O}$ corolário do princípio de determinação do valor por oferta e demanda, desenvolvido no Capítulo 3 ( $\mathrm{O} f$ The Value And Price Of Wares), é que não há preço fixo para qualquer mercadoria. Como veremos, este corolário viria a exercer influência na teoria monetária de Barbon.

O capítulo 4 (Of Mony, Credit And Interest) é de interesse especial para a análise monetária, porque antecipa conceitos a serem posteriormente desenvolvidos em $A$ Discourse Concerning Coining the Money Lighter, de 1696. O capítulo na verdade inicia pela célebre definição estatutária do dinheiro: "Mony is a Value made by a Law; And the Difference of its Value is known by the Stamp, and Size of the Piece" (Barbon, 1690, p. 14). A definição seria reiterada ao longo da obra -"Mony is an Imaginary Value made by a Law, for the Conveniency of Exchange" (Barbon, 1690, p. 18), não restando dúvidas de que o valor do dinheiro é aquele estipulado pelas autoridades.

Barbon especifica duas funções para o dinheiro, a de medida do valor e a de meio de troca. Especificamente, measure of value, change or pawn, sendo de destacar que o termo pawn (prenda, penhor), típico da discussão monetária da época, seria associado por Locke - mas não por Barbon - a algo próximo à concepção moderna de reserva de valor. Em uma espécie de justificativa para a definição estatutária do dinheiro, Barbon esclarece que o dinheiro, exatamente por ser medida de valor e meio de troca, necessita ter seu valor tornado certo por lei. ${ }^{10}$ Vale dizer, a cunhagem ou imposição da estampa tem a função de tornar o valor do dinheiro certo e fixo, sem o que

\footnotetext{
10 "For this Reason, the Value of Mony must be made certain by Law, or else it could not be made a certain Measure, nor an Exchange for the Value of all things."(Barbon, 1690, p. 14).
} 
ele não poderia desempenhar suas funções. Decorre do poder da lei de fixar o valor do dinheiro a ausência de obrigatoriedade de utilização de peças de ouro ou prata como meio circulante. Qualquer símbolo estabelecido pelo legislador pode cumprir as funções do dinheiro. Há neste ponto uma antecipação da proposição central de autores não metalistas, como Law. Como justificar então o uso generalizado de moedas de metal? Barbon atribui a preferência por moedas metálicas à conveniência e à dificuldade de falsificação. Admite ainda que a aceitação generalizada dos metais facilita seu trânsito entre as nações e confere aos mercadores a possibilidade de efetuar arbitragem. Por outro lado, e de modo complementar, à medida que o poder do legislador não atinge a moeda internacional, a forma de determinação do valor da moeda de outros países no território nacional é diversa: a moeda estrangeira vale pelo preço do metal, e não pela estampa, admitindo-se que seu valor varia. ${ }^{11}$

Destaque-se que o texto de 1690 já contém uma crítica à concepção de que o dinheiro tem valor intrínseco. Na visão de Barbon, esta concepção apenas evidencia uma confusão entre o dinheiro, cujo valor é estabelecido por lei, e o ouro e prata, mercadorias cujo valor é incerto e determinado, essencialmente, pela escassez. Ouro e prata são mercadorias, enquanto o dinheiro não é - e tanto não é que as autoridades podem atribuir valor a um simples pedaço de papel.

O tratamento dado por Locke ao crédito e à taxa de juros é parte do capítulo sobre o dinheiro e será aqui deixado de lado, para não nos desviarmos da discussão sobre o valor da moeda. Diga-se apenas que o autor é também pioneiro ao tratar os juros como "renda do capital", à semelhança da renda da terra, e ao estabelecer relação entre juros e lucros em geral, bem como entre juros e renda da terra. E vale assinalar por fim que a possibilidade de determinação da taxa de juros por lei tornou Barbon um defensor da proposta de redução dos juros em tramitação no Parlamento, em oposição a Locke.

A Discourse Concerning Coining the New Money Lighter, de 1696, é um texto inteiramente dedicado à defesa da "valorização do dinheiro", no episódio inglês de recunhagem descrito na seção anterior. Barbon ataca Locke por este se haver oposto à "valorização do dinheiro" (ou desvalorização do meio circulante), assim como à fixação

11 "Therefore, all Foreign Coins go by Weight, and are of no certain Value, but rise and fall with the Price of the Metal." (Barbon, 1690, p. 14). 
da taxa de juros por lei. Os argumentos de Locke, relembrados por Barbon, foram os de que ambos os procedimentos contrariavam a "lei natural", levariam a uma evasão suplementar de meio circulante do país e, adicionalmente, fraudariam contratos estabelecidos, em prejuízo dos proprietários de terra, rentistas e credores em geral, assim como das viúvas, órfãos e outros dependentes de rendas fixas. No Prefácio, Barbon preocupou-se em destacar a isenção e boa fé dos debatedores, passando imediatamente, nas diversas seções ou pequenos capítulos que compõem o texto, a sistematizar os argumentos seus e os de Locke, para afinal concluir pela defesa de posições em política econômica.

As opiniões de Barbon estão inicialmente apresentadas em uma seção curta, intitulada The Contrary Propositions in Answer to Mr. Locke are these, cujos principais tópicos são:

- a prata não tem qualquer valor intrínseco ou fixo, qualquer "... certain estimate that common consent hath placed on it;" (Barbon, 1696, p. 158). A prata é apenas uma mercadoria, e seu valor varia como o de qualquer mercadoria;

- o dinheiro - e não a prata - é o instrumento e a medida do comércio. E isso ele é pela autoridade governamental e pelo selo estampado pelo governo em cada peça de moeda;

- o dinheiro difere da prata não cunhada exatamente pelo valor fixo nela posto pelo governo. Mais importante ainda, o valor estipulado pelo governo em geral excede o valor de mercado da prata;

- os contratos, as transações, as trocas e as estimativas do valor das outras mercadorias são efetuadas por meio de dinheiro, e não da prata. Em resumo, o dinheiro cunhado (e não a prata) é o instrumento dos contratos;

- a "valorização do dinheiro" não irá elevar a taxa de câmbio, nem o preço das mercadorias estrangeiras. Ademais, a "valorização do dinheiro" seria o único meio de evitar a evasão do dinheiro;

- a "valorização do dinheiro" é uma prática efetuada por todos os governos, de tempos em tempos, em função da tendência de longo prazo da prata a subir de valor. As "valorizações do dinheiro" não elevam o preço das mercadorias. A falta de valorização é que carrearia metais (na forma de bullion) para o exterior;

- nem proprietários de terra nem credores perdem com a "valorização do dinheiro"; 
- a manutenção do valor do dinheiro - tese de Locke contrária à "valorização" - reduziria a quantidade de dinheiro em circulação e produziria deflação. Esta, por sua vez, provocaria queda da renda da terra e disseminaria a pobreza.

Os tópicos acima apresentados sucedem a uma apresentação das ideias de Locke (a serem expostas adiante) e antecedem uma fundamentação de cada argumento, em seções bem mais longas. Na impossibilidade de comentar todas as diversas contribuições econômicas de Barbon, vou me ater apenas aos argumentos essenciais à discussão do valor do dinheiro.

Destaque-se de início que o ponto de partida é a crítica à tese lockeana de valor intrínseco do dinheiro estabelecido pelo "consentimento comum", que se apoia tanto em ironias a respeito da natureza do "acordo" que atribuiu à moeda seu valor, ${ }^{12}$ quanto em razões teóricas e substanciais, a saber: nada tem valor intrínseco; o valor é determinado por escassez e abundância; variações no valor de uma mercadoria não afetam o valor de outras de que não sejam substitutas; o valor da moeda é estabelecido pela autoridade; o dinheiro - e não a prata - é o instrumento dos contratos.

Esta última proposição tem uma implicação importante, já que Locke defende a tese de que os contratos se referem em última análise às quantidades de prata proporcionada pela moeda em que são expressos, ao que Barbon contra-argumenta (não desprovido de razão) que, se assim fosse, os contratos seriam estabelecidos diretamente em pesos de metal, e não em preços. Em resumo, a fórmula de Locke levaria a que os preços - valores referidos a quantidades de unidades monetárias - não fossem elementos essenciais ao mundo mercantil.

Um desdobramento original - e controverso - das teses de Barbon encontra-se no tratamento conferido ao "par of money", ou seja, à relação de troca entre duas peças de moeda de diferentes nações. Locke, seguindo a opinião dos economistas monetários e especialistas

12 "If he (Locke) means that by the Estimate that Common consent hath placed on Silver, that Mankind have agreed to set a certain and fixt Price upon Silver; he ought to have given account how and when they made such agreement..." (Barbon, 1696, p. 163). Galeani (1751) repisaria os mesmos chistes, em frases como "onde e quando se reuniu a assembleia que estabeleceu a moeda e seu valor?". 
em comércio, sustenta que o "par of money" baseia-se na equivalência do peso de metal puro (prata, ouro) em cada peça. Barbon, aliás, admite ser esta a "opinião geral".

No entanto, maliciosamente acrescenta que se trata de uma opinião defendida por pessoas com pouca experiência no comércio internacional. Os homens práticos sabem que o "par of money" é estabelecido "... by computing the Valuation that the several Governments set on their Coins; which is not from the equal Quantity of Silver in each piece of money" (Barbon, 1696, p. 167). Vale dizer, o valor estampado por cada governo é que serviria de base para a comparação entre o valor relativo das moedas nacionais, no que vem a ser uma exacerbação infundada da ideia de "valor estabelecido pela legislação", com consequências no tratamento da taxa de câmbio, como veremos.

Como suporte a sua posição sobre o "par of money", Barbon defende a curiosa tese - contrária à opinião de todos os economistas monetários de destaque do final do século XVII e do século XVIII, inclusive os extremamente práticos, como Cantillon - de que na realidade é dificílimo conhecer o efetivo conteúdo em prata e ouro de uma peça monetária. Peso, liga, proporção de metal precioso em cada peça, seriam segredos profissionais guardados pelos mais experientes oficiais das casas da moeda e goldsmiths. Algo fora do conhecimento do homem comum e mesmo de experientes comerciantes internacionais. ${ }^{13}$

A posição a respeito da relação entre o valor estampado na moeda e o valor efetivo dos metais é igualmente importante. Como vimos, Barbon considera que quase todas as peças, cunhadas por diversos estados, estampam um valor acima do valor de mercado do ouro e da prata contidos na peça - a margem admitida é 10 a 15\%. As razões dessa espécie de apreciação do valor da moeda em relação ao valor de seu conteúdo metálico são diversas. Em primeiro lugar, o governo tem que se ressarcir pelos custos de cunhagem. Além disso, como "Tis the Publick Authority upon the Metal that makes it Money" (Barbon, 1696, p. 170), cobra-se um preço, ou taxa de senhoriagem, pela autoridade pública.

13 O que não impede o comércio, porque "It is the currency of the Coin that all men regard more than the quantity of the Silver in it: For the difference of the Fineness of the Silver, and the number of the grains in each piece of Silver, few persons are acquainted with. Not one in a thousand can tell how many grains of fine Silver there are in a Crown, Halfcrown, Shilling, or Sixpence." (Barbon, 1696, p. 172). 
Barbon acrescenta que a margem adicional sobre o valor do metal evita que os governos tenham que alterar com frequência o valor da moeda, diante da tendência contínua à subida de valor da prata. ${ }^{14}$ A rigor, Barbon admite que a moeda de prata é frequentemente sobrevalorizada em relação ao valor de mercado do metal, enquanto as peças de ouro tendem a estampar um valor mais próximo ao valor de mercado do metal. O maior valor por unidade de peso faz com que o mercado não sancione divergências significativas entre o valor de face das moedas de ouro e o preço corrente do metal.

Ao analisar o que determina o tamanho da margem, no entanto, Barbon é levado a superar a ideia de que a fixação do valor da moeda acima do valor do metal é apenas uma medida acautelatória face à valorização constante da prata. Admite que 10 a $15 \%$ é a margem adequada para evitar especulação com o metal, bem como para desestimular a falsificação da moeda, que tem um custo. Enfim, uma Mint rate que proporcionasse uma margem superior a 10 ou $15 \%$ estimularia os fraudadores - que incorreriam nos riscos legais de converter metal em uma peça com valor bem superior - e provocaria um super afluxo de bullion à Casa da Moeda. Inversamente, uma margem pequena poderia provocar a drenagem de metal para o exterior, uma vez que a margem de 10 a $15 \%$ acima do preço de mercado do metal seria adotada por todas as Casas da Moeda. A rigor, a concorrência internacional força os governos a praticarem margens semelhantes, afora momentos excepcionais (guerras, necessidades extremas de recursos que levam a uma elevação da senhoriagem).

É evidente que, ao admitir que todas as nações estabelecem uma margem semelhante de sobre-preço da moeda em relação ao preço corrente do metal, Barbon aduz um argumento contrário a sua tese original de que os governos têm autoridade para fixar o valor da moeda nacional. No fundo, acaba por limitar a proposição de que "Mony is a Value made by a Law" (Barbon, 1690, p. 14), uma vez que, no mundo real, a concorrência e a necessidade de preservar o meio circulante nacional imporiam aos governos os valores estabelecidos no mercado internacional. Estes, por sua vez, decorrem do preço de mercado dos metais e da prática de contínua "valorização do dinheiro" dos governos. Em resumo, Barbon expulsou a ideia de

${ }^{14} \mathrm{E}$ nisso Barbon diverge totalmente de autores de grande autoridade, que sustentam que a prata manifestou uma tendência secular à queda de valor, desde a descoberta da América. Ver Law (1705).

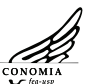


que o preço do metal determina o valor da moeda pela porta da frente, para fazê-la retornar pela porta dos fundos.

Desnecessário acrescentar que o mesmo argumento - concorrência internacional - destrói a explicação dada ao "par of money". Como vimos, a explicação de Barbon baseia-se em última análise no argumento simplório de que os comerciantes e especuladores desconhecem o valor do metal contido em cada moeda. Ora, se a arbitragem internacional funciona de modo tão eficiente, não há razões para duvidar que o mercado internacional de moedas e metais seja operado por pessoas com bom conhecimento de valor das moedas, peso em metal, ligas metálicas, taxa de câmbio; enfim, do dia-a-dia do trade. ${ }^{15}$

Locke argumenta que a "valorização do dinheiro" produziria drenagem de prata para o exterior, devido ao déficit do balanço de pagamentos e à decorrente compensação por meio de movimentos de metal. Em relação à compensação dos desequilíbrios do "balance of trade" pelo fluxo de metais preciosos, Locke apenas aplicou uma espécie de senso comum dos economistas dos séculos XVII e XVIII, já de largo trânsito no pensamento mercantilista: nações que não dispõem de minas somente podem obter os metais que são a base do meio circulante e da riqueza através de superávits na balança de comércio. ${ }^{16}$ Trata-se de uma tese elementar, garantida na vida econômica real por um sistema de ajustamento entre taxas de câmbio, preço de mercado de títulos de comércio exterior e Mint rates. Um sistema de certa complexidade, porém perfeitamente operacional e bem reconhecido pelos especialistas. ${ }^{17}$ Novamente, contra a opinião dos especialistas, Barbon não concorda que os saldos da balança mercantil sejam compensados por metais:

\footnotetext{
15 Qualquer dúvida sobre as práticas e qualificações requeridas de um bom mercador pode ser desfeita pelo capítulo primeiro (The Qualities which are required in a perfect Merchant of Forraign Trade) do celebrado livro de Mun, England's Treasure by Forraign Trade (Mun, 1664).

${ }^{16} \mathrm{Com}$ a ressalva da associação de tesouro à riqueza, esta é a formulação emblemática de Mun (1664): "The ordinary means ... to increase our wealth and treasure is by Forraign Trade, wherein wee must ever observe this rule; to sell more to strangers yearly than wee consume of theirs in value." Mun (1664), p. 5.

${ }^{17}$ Cantillon apresenta uma boa descrição dos mecanismos de ajustamento. Lembremos que o Ensaio sobre a Natureza do Comércio em Geral de Cantillon foi escrita por volta de 1730 e que o autor dispunha de grande conhecimento das práticas comerciais, monetárias, financeiras de seu tempo. A respeito, veja-se Murphy (1988). A rigor, o próprio texto de Locke (Some Considerations) dá uma ideia dos mecanismos econômicos e financeiros por detrás do ajustamento da taxa de câmbio.
} 
"... the Balance of all Foreign Accompts, as he (Locke) supposes, are paid in Money, which must be sent out to balance the Accompt. ... This is a very popular Notion ... yet if it be consider'd, it will be found to be a mistake, and that there is no such Usage as Balancing the Foreign Accompts of Merchants, by the Money of a Foreign Nation;..." (Barbon, 1696, p. 175).

Mais grave do que a discordância é o teor dos argumentos utilizados em sua sustentação, os quais iniciam pela negação do princípio mercantilista de que a riqueza é constituída por metais preciosos para desembocar afinal na constatação de que é impossível aferir o balanço de comércio de uma nação. De acordo com Barbon, os números seriam incertos, as estatísticas das alfândegas pouco confiáveis e, finalmente, os movimentos da taxa de câmbio não revelariam o que se passa com a balança de comércio. Além disso, ainda que pudéssemos aferir o saldo comercial, conclui, não é verdade que eles sejam compensados com bullion - podem ser compensados em matériasprimas ou em outros metais que não o ouro e a prata, mercadorias que igualmente representam riqueza. ${ }^{18}$

Segue-se um pioneiro ataque ao protecionismo, o qual, no entanto, é acompanhado de uma duvidosa máxima da época: todo o comércio exterior fundamenta-se nas matérias básicas (staple commodities) dos países. O país exporta apenas a produção que excede a capacidade de consumo nacional dos diversos produtos. Enfim, trocam-se matérias básicas por matérias básicas, e assim se desenvolve a produção e circula a riqueza. Esta era a ingênua máxima, de largo curso até o início do século XVII, utilizada para certificar que o comércio exterior apenas acresce à riqueza das nações, sem provocar desabastecimento. Vende-se apenas o excedente. Deixando de lado o acerto ou equívoco de tais argumentos, é certo que eles não conseguem contornar a relação essencial entre saldos cambiais e movimento de metais preciosos.

O curioso é que Barbon chega, a despeito da sinuosa argumentação, a uma síntese que não deixa de ser satisfatória em seus dois elementos centrais, quais sejam, o de que o dinheiro e o bullion movem-se de

${ }^{18}$ Curiosamente, o argumento de Barbon sobre o ajustamento do balance of trade, que coloca lado a lado (e na condição de mercadorias) os metais e as mercadorias diversas, lembra o célebre tratamento do ajustamento do balanço de pagamentos de Ricardo, em The High Price of Bullion (Ricardo, 1810). 
um país a outro por movimentos de arbitragem orientados pelo lucro dos comerciantes de metal, e o de que existe uma relação entre taxa de câmbio e preços nacionais, relação que orienta as transferências de metais. Pois bem, tão razoável conclusão não o impede de conservar a opinião de que os movimentos de metais não são produzidos por déficits ou superávits no balance of trade (se é que existe balance of trade...). Seriam produzidos pela diferença de valor do bullion entre os países - o que é verdadeiro, porém, acompanha os movimentos do balance of trade - e pela busca de lucro dos negociantes de metais o que é igualmente verdadeiro, mas apenas especifica o mecanismo de equilíbrio e formação de preços no mercado de metais.

Já na discussão final das causas e efeitos do "raising the value of money", Barbon é bem mais persuasivo. Reitera que se trata de uma prática disseminada e ancestral dos governos. Insiste em que os governos fixam o valor do dinheiro em não mais de 10 a $15 \%$ em excesso ao valor dos metais - margens maiores estimulariam a falsificação da moeda, a despeito das penalidades. Relembra que margens menores implicariam modificações do valor da moeda em prazos muito curtos. Conclui assim que "... the Government cannot raise their Money as high as they please..." (Barbon, 1696, p. 193), conclusão utilizada, paradoxalmente, contra Locke, por haver este afirmado que a sanha valorizadora dos governos seria ilimitada se eles tivessem o poder de alterar o valor da moeda. Manobras argumentativas à parte, Barbon chegou ao ponto de Locke, qual seja, admitir que o poder dos estados em política monetária é limitado.

Para Barbon, as razões de fundo para "valorizar o dinheiro" são duas: a valorização dos metais preciosos, em decorrência de sua escassez e da alta demanda, e a ocorrência de necessidades extraordinárias de financiamento público. A concorrência internacional força uma valorização conjunta das moedas nacionais, embora a Inglaterra tenha sistematicamente praticado uma subvalorização da moeda de prata, causa última de sua escassez - vê-se que o relato condiz com a realidade histórica. A moeda de ouro inglesa não sofreu evasão, graças ao maior comprometimento das autoridades monetárias com o valor de mercado do ouro.

A conclusão final é que a "valorização do dinheiro" provocará aumento do meio circulante nacional. Note-se que se trata de uma conclusão de certo modo obrigatória, por dois motivos: por um lado, 
a concorrência internacional força os países a valorizarem o dinheiro - o país que não valorizasse o dinheiro diante de concorrentes tenderia a perder moeda e a não conseguir carrear bullion para sua casa da moeda; por outro, por uma trivial razão algébrica: a desvalorização do meio circulante em relação ao padrão monetário faz com que uma mesma quantidade de metal transforme-se em mais unidades monetárias.

A proposta de Barbon, como a de Lowndes, visa a adequar o valor da moeda à realidade de um meio circulante deteriorado. Em função da deterioração do meio circulante, a nova moeda (no mesmo valor) tem que conter menos metal, sob pena de se produzir evasão de moeda e deflação. Enfim, a "valorização do dinheiro" é impositiva.

Ao argumento de Locke de que uma "valorização do dinheiro" apenas tenderia a elevar o preço de todas as mercadorias, Barbon contrapõe sua concepção, anteriormente mencionada, de que o preço de uma mercadoria não influencia o de outra que não seja concorrente. Assim, o preço da moeda não pode influenciar o do grão e o de outras mercadorias. ${ }^{19}$ Barbon rejeita a teoria quantitativa da moeda, com a prosaica constatação de que, se os preços dependessem do conteúdo metálico da moeda, o preço das mercadorias só poderia se alterar quando o do dinheiro variasse. Em sua visão, algumas mercadorias variam incessantemente de preço (os grãos, por exemplo), enquanto outras têm preço fixo (a cerveja, as manufaturas de modo geral).

As constantes modificações dos preços relativos - provocadas pelas condições de oferta e demanda nos diversos mercados - seriam a evidência de que as variações de preços não podem ser atribuídas a alterações do valor do dinheiro. Vê-se que, sob a capa do aforismo "o preço de uma mercadoria não pode afetar o de outra que não seja concorrente" abrigam-se mudanças de preços relativos e alterações do nível geral de preços. Diga-se que a confusão entre flutuações dos preços relativos e alterações do nível geral de preços é de certo modo compreensível, pelo fato de a própria moeda ter um preço em sistemas metálicos: a relação de troca entre as peças que compõem o meio circulante e o padrão monetário oficial, ou relação entre "moeda real" e "moeda ideal".

19 “... Corn it is evident do's not rise or fall by the difference of more or less plenty of Money; but, by the plenty and scarcity that God gives" (Barbon, 1696, p. 201). 


\section{Os Pontos Fortes na Argumentação de Locke}

O ponto forte da crítica de Barbon a Locke reside na conclusão de que a manutenção do conteúdo metálico da moeda e a objeção à "valorização do dinheiro" representariam uma severa constrição do meio circulante. Kelly procura efetuar um balanço dos possíveis efeitos das medidas opostas (valorizar ou não valorizar o dinheiro) e conclui que a profusão de fatores concretos a exercerem impactos no meio circulante e no nível de produção na década de 1690 - orçamento e crédito público, estado do comércio internacional, situação das safras... - torna difícil uma opinião taxativa sobre os impactos de uma e outra política. De todo modo, não há como negar que, sob o ponto de vista conceitual, a proposta de Locke era deflacionista, enquanto a proposta defendida por Barbon era neutra, ou não deflacionista. ${ }^{20}$

Do mesmo modo, Barbon tinha razão em sustentar que a "valorização do dinheiro" seria menos propensa a alimentar o fluxo de prata para o exterior do que a oposta política de sustentação do conteúdo metálico da moeda aos níveis teóricos do período anterior ao de crise. Afinal, a moeda em circulação já havia sido erodida. Não havia em circulação moedas com valor "cheio". A recunhagem com sustentação dos padrões pré-crise representaria uma eliminação de meio circulante.

Apesar do acerto das conclusões, o núcleo teórico da argumentação de Barbon não é isento de dubiedades. Como vimos, a ideia de que o valor do dinheiro é definido pela legislação vê-se logo atenuada pela admissão de que existe uma margem definida e não muito larga para a "valorização do dinheiro" regularmente praticada pelos estados. ${ }^{21}$ Os movimentos de arbitragem policiam os valores das moedas nacionais. O "par of money", a princípio considerado dependente apenas do valor estampado às peças monetárias, afinal não pode afastar-se tanto assim do conteúdo metálico das moedas.

Quanto ao tratamento da taxa de câmbio, Coining the Money Lighter... é um texto surpreendentemente obscuro. Barbon não sabe, aliás, se podemos até mesmo admitir a existência de um balance of trade. Como vimos, apoia-se para tanto em uma combinação de

\footnotetext{
${ }^{20}$ A respeito, ver Vickers (1968).

${ }^{21} \mathrm{Na}$ crise de 1695/96, a valorização proposta era maior - cerca de $20 \%$ - devido à deterioração do meio circulante e ao retardamento da Inglaterra na adoção de correções no valor do dinheiro, recomendadas pelo preço de mercado da prata.
} 
argumentos anti mercantilistas com agnosticismo ingênuo a respeito das reais condições em que opera o comércio internacional de mercadorias, metais e títulos. Em certas circunstâncias, tal combinação dificulta a aceitação, ou obscurece a exposição, da lógica dos ajustamentos naturais. E na obediência à lógica dos ajustamentos naturais e no primado dos princípios sobre os casos particulares residem os méritos da análise monetária de Locke.

A teoria monetária de Locke é ancorada por dois elementos. Em primeiro lugar, por uma concepção cheia de nuances de moeda e funções da moeda, contrato, preservação de valor. Esta concepção, que remete a uma complexa fundamentação político-filosófica, anterior e de certo modo externa à obra econômica do autor, será abordada na próxima seção.

Em segundo lugar, por uma combinação de senso comum econômico e lógica rigorosa. O senso comum reside na admissão das ideias difusas sobre balanço de pagamentos e meio circulante, principalmente a de que o comércio internacional representava o principal fator de expansão e contração monetária. A lógica está representada pela sustentação de dois princípios que viriam a desempenhar um papel importante no pensamento econômico do século XVIII: a teoria quantitativa da moeda e uma versão embrionária do mecanismo de ajustamento automático do balanço de pagamentos.

A teoria quantitativa da moeda liga o nível de preços à oferta monetária; o specie-flow mechanism relaciona a oferta monetária às condições do comércio internacional, mostrando como se produz o ajustamento entre oferta monetária, nível de preços e taxa de câmbio.

A rigor, foi com o suporte destes elementos lógicos que Locke sustentou sua defesa rigorosa dos contratos, assim como sua rejeição à ideia - sensível a Barbon - de que o governo tem poder de arbítrio sobre as variáveis econômicas, principalmente o valor do dinheiro. No caso da taxa de juros, é fácil perceber como opera essa teoria dos contratos reforçada pela lógica econômica. Locke simplesmente supõe que, na medida em que o nível dos juros é determinado por oferta e demanda de moeda, o controle por lei viria a afetar um ou outro lado - oferta ou demanda -, revelando-se ineficaz e impraticável. ${ }^{22}$

\footnotetext{
${ }^{22} \mathrm{O}$ controle da taxa de juros levaria as aplicações a canais obscuros e não legais, o que contornaria os impedimentos legais. Provocaria ainda o efeito deletério de estimular o perjúrio.
} 
No caso do valor do dinheiro, a explicação é menos simples. Para Locke, uma "valorização do dinheiro" apenas elevaria o nível de preços - já que as peças monetárias afetadas passam a valer menos. A elevação do nível de preços, por sua vez, ativaria movimentos corretivos da taxa de câmbio e do balance of trade, os quais repercutiriam na oferta monetária. A lição de Locke é a de que não se deve pretender desviar o dinheiro de seu "valor natural".

O dilema reside na definição do "valor natural" - algo que emana de um pacto societário. A concepção lockeana de valor determinado "pelo consentimento" em princípio retira do dinheiro o caráter de mercadoria. Temos aqui uma fórmula complexa - até mesmo obscura -, que tanto desagrada a quem acredita que o valor do dinheiro resulta de imposição legal, como Barbon, como àqueles que não aceitam a existência de um "valor imaginário" determinado por consentimento, nem acreditam que o conhecido território teórico do valor das mercadorias seja uma base inadequada para se discutir o valor do dinheiro. Daí o desconforto de tantos economistas com o "valor imaginário" de Locke.

Acrescente-se que os economistas que consideram estar o valor do dinheiro fundamentado no valor dos metais não partilham uma única teoria do valor. Hipóteses diversas sobre o valor das mercadorias são admitidas: oferta e demanda (Turgot), escassez (Galiani), custos de produção e fertilidade das minas (Cantillon, em parte Galiani).

O denominador comum é a aceitação de que o valor do dinheiro não pode fugir de seu valor como mercadoria - ou como metal precioso. A despeito da razoável opacidade da ideia de "valor determinado pelo consentimento comum", a lógica dos ajustamentos naturais nos mercados é o ponto forte da argumentação de Locke. É esta lógica, aliás, que na discussão sobre a determinação do "par of money" acaba por afastar Barbon de suas opiniões preliminares e extremadas sobre a capacidade de imposição de valor ao dinheiro pelos governos. 


\section{Conclusões}

Coining the Money Lighter inicia com uma síntese das ideias monetárias de Locke (na versão de Barbon), apresentada logo após o prefácio. Os principais pontos desta síntese, da seção The Contents, or, Chief Substance of Mr. Lock's Book são os seguintes:

- o valor intrínseco da prata é a estimativa nela posta pelo consentimento comum; ${ }^{23}$

- a prata - e não a moeda - é o instrumento dos contratos (Locke considerou que o peso em prata da moeda é subjacente aos contratos); ${ }^{24}$

- a diferença entre o dinheiro e uma peça de prata não cunhada reside apenas na estampa, ou seja, o dinheiro é apenas um peso em metal com estampa;

- o par of money põe em relação os pesos de metal precioso contidos em duas moedas nacionais;

- a quantidade de meio circulante depende do balance of trade;

- a "valorização do dinheiro" provocaria uma perda para os credores e proprietários de terra;

- determinada quantidade de prata tem sempre o mesmo valor de uma igual quantidade de prata; 25

- a "valorização do dinheiro" provocará uma elevação proporcional nos preços de todas as mercadorias. Como as pessoas contratam pela quantidade de prata, existindo menos prata na peça de moeda, ela comprará menor quantidade de bens;

- a taxa de câmbio, como o "par of money", obedece à quantidade de prata contida nas moedas nacionais;

- a "valorização do dinheiro" não impede a evasão de dinheiro, a qual depende unicamente do saldo do balance of trade;

\footnotetext{
${ }^{23}$ A rigor, para Locke o valor intrínseco dos dois metais preciosos utilizados como moeda - ouro e prata - decorreria do consentimento comum. Locke acaba por se ater à prata, por ser este metal o padrão dos principais sistemas monetários de seu tempo, e também em razão da preocupação com a estabilidade do valor da moeda. Mais sobre ouro, prata, estabilidade, adiante.

24 "Men in their bargains contract not for denominations or sounds, but for the intrinsic value, which is the quantity of silver, by public authority warranted to be in pieces of such denomination." (Locke, 1696, p. 95).

${ }^{25}$ Locke de fato insiste neste truísmo, adiante comentado.
} 
Verificar em que medida a síntese de Barbon é fiel às ideias de Locke requer uma breve exposição dos principais elementos da teoria monetária deste último autor. A exposição não fará jus à riqueza de temas monetários dos ensaios de Locke, concentrando-se em poucos, porém decisivos, pontos: valor do dinheiro, valor intrínseco, funções do dinheiro. Iniciemos pelo valor do dinheiro, pois, como foi visto, é generalizada a objeção às ideias de "consentimento geral" e "valor imaginário", associadas por Locke à prata amoedada. Vale retomar a primeira e sugestiva referência ao "consentimento geral" em Some Considerations..., em uma passagem que explicita a diversidade de temas presentes no tratamento do valor da moeda. A passagem trata da tradicional discussão da "... necessidade de uma certa proporção de dinheiro para comércio ..." (Locke, 1691, p. 14), na qual Locke descreve a circulação do dinheiro pelas mãos dos proprietários de terra, dos mercadores etc, para, finalmente, chegar às funções do dinheiro. A célebre fórmula de Locke é a de que o dinheiro serve "... for counters and for pledges...", e fica claro que a proporção entre dinheiro e comércio refere-se ao seu papel como um pledge. O pledge, por sua vez, implica preservação de valor - algo que Locke associa ao dinheiro em forma metálica.

Mais precisamente, para Locke uma das funções da moeda (counter) envolve "reckoning", enquanto a outra (pledge) envolve "security". O "reckoning" é assegurado pela estampa; já o "security" não pode prescindir da existência de "valor intrínseco" no dinheiro. ${ }^{26}$ É este valor intrínseco, relacionado à função de pledge, que se reporta ao consentimento e ao valor imaginário. A passagem a seguir é elucidativa:

"For mankind, having consented to put an imaginary value upon gold and silver, by reason of their durableness, scarcity, and not being very liable to be counterfeited, have made them, by general consent, the common pledges, whereby men are assured, in exchange for them, to receive equally valuable things, to those they parted with, for any quantity of these metals; by which means it comes to pass, that the intrinsic value regarded in these metals, made the common barter, is nothing but the quantity which men give or receive for them; for they having, as money, no other value, but as pledges to procure what one wants or desires, and they procuring what we want of desire,

26 "... so carrying with it even reckoning and security; that he that receives it shall have the same value for it again, or other things that he wants, whenever he pleases. The one of these it does by its stamp and denomination; the other by its intrinsic value, which is its quantity." (Locke, 1691, p. 14/15). 
only by their quantity, it is evident that the intrinsic value of silver and gold used in commerce, is nothing but their quantity." (Locke, 1691, p. 14).

A passagem assinala diversas questões importantes, todas pertinentes ao contencioso Barbon versus Locke. São elas:

1. A humanidade atribui um valor imaginário tanto ao ouro quanto à prata, ou seja, a todos os metais preciosos acolhidos como moeda; ${ }^{27}$

2. A especificação das funções do dinheiro, e da relação especial entre conteúdo metálico da moeda e pledge;

3. O reconhecimento de que basta o símbolo público (stamp) para contagem e medida - reckoning;

4. O valor intrínseco do dinheiro é "nada senão sua quantidade" fórmula recorrente de Locke - apenas em relação ao papel de pledge;

5. O pledge é a base da equivalência (igual valor), possuindo o termo equivalência duplo sentido: i) representa a garantia de que o proprietário de certa quantidade de dinheiro receberá sempre com ela "coisas igualmente valiosas" - quase um truísmo; ii) implica a preservação do valor no tempo. A preservação do valor no tempo é o ponto verdadeiramente espinhoso, porque não há meio de garanti-la, uma vez que nenhum objeto tem valor invariável.

Cabe assinalar que a fundamentação do "valor intrínseco" pelo "consentimento geral" não é passageira. É, pelo contrário, permanente. Locke a reitera em Further Considerations..., um texto imerso nos aspectos concretos da crise monetária inglesa: "The intrinsic value of silver, considered as money, is that estimate which common consent has placed on it, whereby it is made equivalent to all other things ..." (Locke, 1696, p. 82); ou ainda "... silver is that which mankind have agreed on, to take and give in exchange for all commodities as an equivalent." (Locke, 1696, p. 90). Voltemos à afirmação de que o valor do dinheiro é "nothing but quantity". Ela está associada ao dinheiro enquanto pledge, e o valor é "nothing but its quantity" porque

${ }^{27}$ Locke depois vai se restringir ao valor imaginário da prata, por ser esta a base do sistema monetário inglês. Não é verdadeira, portanto, a opinião de Barbon de que Locke em princípio considera o ouro como mercadoria e prata como algo especial. Mais sobre ouro e prata como mercadorias, adiante. 
"... an equal quantity of silver is always of equal value to an equal quantity of silver" (Locke, 1696, p. 82). Não sem razão, Barbon considera vazia esta fórmula. ${ }^{28}$

No entanto, cabe lembrar que por ela Locke assinala um tema trivial em economia monetária, a saber, a uniformidade dos metais preciosos - o que faz com que $100 \mathrm{~g}$ de ouro ou prata sejam sempre iguais a $100 \mathrm{~g}$ de ouro ou prata de mesma liga. Peças de mesma liga podem ser comparadas por seu peso. Em suma, Locke quer se referir à conhecida constatação de que o metal precioso é uma boa medida de valor e um bom meio de comparação e preservação de riqueza por ser uniforme, enquanto as demais mercadorias não são - um boi difere de outro boi. Dada a uniformidade, para as moedas, uma escala de peso é imediatamente uma escala de valores.

Porém, uniformidade não é tudo. Além de sua uniformidade, "... silver is a measure of a nature quite different from all other" (Locke, 1696, p. 83), por uma razão especial: a moeda atua como medida de valor e é ao mesmo tempo "... the thing bargained for", ou seja, é o instrumento universal de troca. Nas palavras de Locke, "... it is the instrument, as well as measure of commerce" (Locke, 1696, p. 83). Como instrumento de comércio, detém a capacidade de preservar o valor. Para Locke, o dinheiro é um pledge exatamente por ser capaz de comandar coisas de mesmo valor a qualquer tempo.

Note-se que o pledge lockeano tem atribuições imensas, que transcendem até mesmo a acepção habitual conferida à função de reserva de valor do dinheiro. Sabe-se que nada pode garantir a existência de uma reserva de valor - até mesmo uma moeda com estampa definida e conteúdo metálico invariável - imune a variações de valor. A admissão de que a moeda é mercadoria torna claro que a invariabilidade do valor é uma qualidade inatingível. Sabemos que Barbon não admite que a moeda seja uma mercadoria. E Locke? É correto afirmar que ele definitivamente descarta a possibilidade de o dinheiro ser considerado uma mercadoria?

\footnotetext{
28 "And if a man should offer to buy goods in the market by saying, I'll give so many grains, ounces, or pounds of silver; he would be presently asked, what is silver worth an ounce? And would be no more understood by Mr. Lock's answer. That an ounce of silver is worth an ounce of silver, than if a country-man in a market being ask'd, what is corn worth a bushel? Should say, 'Tis' worth a bushel of corn." (Barbon, 1696, p. 166/167).
} 
A resposta não é tão simples. Há outras possibilidades, como se pode perceber na exposição da famosa "teoria dual do valor do dinheiro" - o dinheiro vale porque proporciona juros e porque permite comandar outros bens. No âmbito da "teoria dual", ao discutir as consequências negativas de se pretender rebaixar a taxa de juros por lei, Locke assinala que a redução do preço do dinheiro provocada pelo rebaixamento dos juros, além de prejudicar o comércio, elevará o preço das mercadorias: "... the lowering of interest will raise the value of all other things in proportion"(Locke, 1691, p. 19). ${ }^{29}$ A razão é simples: já que o dinheiro é a contrapartida (counterbalance) de todas as coisas que pode comprar, "... as much as you take off from the value of money, so much you add to the price of other things which are exchanged for it ..." (Locke, 1691, p. 19). Neste contexto, vale dizer, em proporção às mercadorias que pode adquirir, o valor do dinheiro segue a regra geral (oferta $\mathrm{x}$ demanda): "... the quantity of the ready money we have in comparison with the quantity of that thing, and its vent; or ... the price of any commodity rises or falls by the proportion of the number of buyers and sellers ..." (Locke, 1691, p. 20).

Mais ainda, neste contexto o valor do dinheiro reside em sua capacidade de nos proporcionar bens. E nisso "... it has the nature of a commodity; only with this difference, that it serves us commonly by its exchange, never almost by its consumption." (Locke, 1691, p. 22). Além disso, em tal situação o dinheiro "... has not at all a more standing settled value, in exchange with any other thing, than any other commodity; but a more known one..."(Locke, 1691, p. 22). ${ }^{30}$ Quer dizer, na compra e na venda de mercadorias, o valor do dinheiro varia como o de qualquer mercadoria. Por mero costume admite-se que o valor da mercadoria que comanda - e não o seu - variou.

Em suma, em certas situações e contextos o valor do dinheiro varia; em outras, não. Além disso, Locke não estabelece conexão entre valor de mercado (marketable value) e valor intrínseco (intrinsic, natural worth of any thing). O valor de mercado é uma proporção de troca. Se trocamos duas toneladas de trigo por dez vacas, os dois conjuntos são "de igual valor" (of equal worth). Já o valor natural de qualquer coisa "... consists in its fitness to supply the necessities ..." (Locke, 1691, p. 27). O valor de mercado é proporção, o valor intrín-

\footnotetext{
${ }^{29}$ Deixo sem discussão a relação entre juros e preço das mercadorias.

30 "Money, therefore, in buying and selling, being perfectly in the same condition with other commodities, and subject to all the same laws of value, ..." (Locke, 1691, p. 23).
} 
seco, qualidade. ${ }^{31}$ Ao valor de mercado se aplica o princípio geral de determinação de valor, oferta versus demanda. ${ }^{32}$

Ainda assim, ou seja, apesar de variar de valor em sua relação com outras mercadorias, o dinheiro permanece "... a standing measure of the falling and rising value of other things; ... and alteration of price is truly in them only." (Locke, 1691, p. 28). Cabe notar que há no mínimo três importantes questões por detrás da standing measure. A primeira delas é a que fora ventilada pelo próprio Locke: quando se altera o preço de uma mercadoria, ainda que tal alteração decorra de mudanças no valor da moeda, é costume atribuí-la à mercadoria. A segunda é a inexistência de uma medida invariável de valor um problema propriamente ricardiano. Locke acredita que uma boa medida de valor deve ter um "standing value", e é por essa razão, inclusive, que descarta a viabilidade e conveniência de sistemas monetários bimetálicos - neles, a variação de valor da unidade monetária é intrínseca e aparente. ${ }^{33} \mathrm{~A}$ terceira (e a meu ver mais pertinente ao universo lockeano) questão está associada à constatação de que alterações no valor do dinheiro não afetam o reckoning, ou contagem. Qualquer unidade de conta, inclusive o papel-moeda, serve ao estabelecimento de escalas de valor. Daí a constatação de que para contagem e medida basta o símbolo (stamp).

Para Locke, o dinheiro perde sua condição de standing measure em apenas uma situação: quando muda sua quantidade em circulação. Se o preço do trigo não se altera porque a relação entre oferta e demanda não mudou, e tivermos mais ou menos dinheiro em circulação; neste caso, "... money alters its worth and wheat does not, though it sell for a greater, or less price,..." (Locke, 1691, p. 28). De modo bem claro, na relação de troca com as mercadorias, o dinheiro varia de valor apenas nas circunstâncias consideradas pela teoria quantitativa do dinheiro, ou seja, mais dinheiro em circulação rebaixa seu valor e vice-versa.

\footnotetext{
31 "The change of this marketable value of any commodity, in respect of another commodity, or in respect of a standing, common measure, is not the altering of any intrinsic value, or quality, in the commodity..." (Locke, 1691, p. 27).

${ }^{32}$ Locke fala em "quantity versus vent", sendo vent uma transação efetuada. Vent não é análogo à demanda. Law (1705) faz uma crítica apurada da fórmula lockeana "quantity versus vent".

33 "... the measure of commerce must be perpetually the same, invariable, and keepin the same proportion of value in all its parts. But so only one metal does... One metal, therefore, alone can be the money of account and contract, and the measure of commerce in any country. The fittest for this use, is silver, for many reasons." (Locke, 1696, p. 90). Escolhida a prata, todos os outros metais, ouro inclusive, tornam-se apenas mercadorias.
} 
Acredito que este breve sumário mostre a complexidade e a diversidade de questões em jogo no tratamento ao valor do dinheiro. $\mathrm{Na}$ verdade, não é difícil perceber que os escritos monetários de Locke representam uma combinação de expertise em assuntos monetários correntes - "valorização do dinheiro", moeda deteriorada, escassez de meio circulante, taxa de câmbio - com a estrutura conceitual do contrato social, sistematizada em Two Treatises of Government (Locke, 1989). A durabilidade do meio de troca e a preservação do valor representam um elemento central desta estrutura conceitual, já que são um meio necessário à acumulação do capital e à legitimação da propriedade concentrada. Pode-se dizer que a invariabilidade do valor do dinheiro é um elemento do trust lockeano. Por sua vez, o trust é a base do pacto societário. Em suma, são sensíveis os vínculos entre o celebrado Capítulo V (Of Property) do Livro II (Of Civil Government) dos Dois Tratados e as atribuições associadas à função monetária de pledge. ${ }^{34}$

Uma palavra final sobre o trust, que é a base do pacto societário e do governo civil. Locke acredita que a "valorização do dinheiro", assim como o rebaixamento da taxa de juros, abalam o trust. O dinheiro é um dos elementos centrais do pacto societário, e Locke vê com profunda preocupação qualquer elemento - mudança arbitrária do valor do dinheiro, fraude do meio circulante - que possa representar ameaça aos contratos econômicos já estabelecidos. ${ }^{35}$

Acredito que os escritos monetários acrescentam à visão lockeana do trust dois elementos. A teoria quantitativa do dinheiro mostra que é inútil alterar voluntariamente o valor do dinheiro; por exemplo, por meio da "valorização". Mais dinheiro em circulação significará a efetiva desvalorização das peças metálicas, ou seja, o encarecimento das mercadorias.

Por sua vez, a variação da taxa de câmbio que sobrevém às mudanças de valor do dinheiro reforça a concepção de que atos do governo não têm o condão de submeter os não súditos; no caso, os estrangeiros e suas moedas. Não há como impor aos estrangeiros qualquer mudança unilateral do valor do dinheiro. A rigor, e mais importante, nem aos nacionais, em função da mobilidade da moeda, da possibilidade de

\footnotetext{
${ }^{34}$ Sobre as conexões entre a filosofia de Locke e sua teoria monetária, Caffentzis (1989).

${ }^{35}$ Locke chega a dizer que o clipping - um ato ilegal - e a money enhancement representam a mesma coisa, fraudar o homem em seu direito. O money enhancement tem o agravante de ser fraude praticado por quem não deveria fazê-lo - a autoridade.
} 
transformá-la em bullion, evadi-la do território nacional. A moeda é um território em que a autoridade do governante é permanentemente contrabalançada - posta em xeque - pelo mercado, ou pelas práticas comerciais correntes.

De resto, ou por sobre sua concepção político-filosófica de pacto societário e de dinheiro, prevalece em Locke o senso comum dos economistas. Este senso comum permite concluir, por meio de uma análise dos diversos mecanismos de arbitragem existentes em uma economia mercantilizada e apoiada em relações monetárias, que o balance of trade determina a oferta monetária, que o par of money é estabelecido no mercado tendo por base o conteúdo metálico das moedas, e que a taxa de câmbio não pode ser arbitrariamente determinada. Enfim, que o "valor estabelecido por lei" de Barbon não passa de uma ficção.

\section{Referências}

Barbon, N. (1996) Discourse Concerning Coining the new Money Lighter - Answer to Mr. Lock's Considerations About Raising the Value of Money (1696). In: Magnusson, L. Mercantilism. Routledge, London.

Barbon, N. A Discourse of Trade (1690). A Reprint of Economic Tracts. Baltimore, The Lord Baltimore Press, 1905. Disponível em: <http://oll.libertyfund.org/title/982. Acesso em: 10/08/2010.

Boyer, J. (2003) La Pensée monétaire - Histoire et Analyse. Paris, Éditions Les Solos, ISBN 2.915224.00.5. Disponível em: http://jdbdr.free.fr/

Caffentzis, C. (1989) Clipped Coins, Abuded Words \& Civil Government - John Locke's Philosophy of Money. New York, Autonomedia.

Cantillon, R. (2001) Essay on the Nature of Commerce in General (1755). London, Transaction Publishers.

Eltis, W. (1995) John Locke, the quantity theory of money and the establishment of a sound currency. In: Blaug, M. (org.). The Quantity Theory of Money - from Locke to Keynes and Friedman. Chippenham, Edward Elgar.

Galiani, F. (2000) Della Moneta (1751). Curitiba, Segesta/Musa.

Hutchison, T. (1988) Before Adam Smith - The Emergence of Political Economy, 1662-1776. Oxford, Basil Blackwell.

Kelly, P. H. (1991) General Introduction: Locke on Money. In: Locke, J. Locke on Money. Oxford, Clarendon Press.

Klindeberger, C. P. (1993) A Financial History of Western Europe, Second Edition. Oxford, Oxford University Press.

Law, J. (1705) Money and Trade Considered: with a proposal for supplying the nation with money. Glasgow, R. \& A. Foulis.

Letwin, W. (1963) The Origins of Scientific Economics: English Economic Thought 1660-1776. London, Methuen. 
Locke, J. Further Considerations Concerning Raising the Value of Money (1696). In: Locke, J. The Works of John Locke in Nine Volumes. London, Rivington, $12^{\text {th }}$ ed., 1824. Disponível em: $<$ http:// oll.libertyfund.org/EBooks/Locke 0128.04.pdf > . Acesso em: 10/08/2010.

Locke, J. Two Treatises of Government (1689). In: Locke, J. The Works of John Locke in Nine Volumes. London, Rivington, $12^{\text {th }}$ ed., 1824. Disponível em: $<$ http://oll.libertyfund.org/EBooks/Locke 0128.04.pdf >. Acesso em 10/08/2010.

Locke, J. Some Considerations of the Consequences of the Lowering of Interest, and Raising the Value of Money (1691). In: Locke, J. The Works of John Locke in Nine Volumes. London, Rivington, $12^{\text {th }}$ ed., 1824. Disponível em: <http://oll.libertyfund.org/EBooks/Locke 0128.04.pdf.> Acesso em: $10 / 08 / 2010$

Mun, T. (1986) England's Treasure by Forraign Trade (1664). N. York, Augustus M. Kelley.

Murphy, A. (1988) Richard Cantillon, entrepreneur and economist. Oxford, Clarendon.

Ricardo, D. The High Price of Bullion.

Schumpeter, J. (1954). History of Economic Analysis. London, Allen \& Unwin, 1986.

Vickers, D. (2008) Nicholas Barbon. In: Durlauf and Blume (eds). The New Palgrave, $2^{\text {nd }}$ Edition. London, Palgrave Macmillan.

Vickers, D. (1968) Studies in the Theory of money 1690-1776. N. York, Augustus M. Kelley. 